\title{
A STUDY ON THE COMMUNICATION METHOD FOR ONLINE PARTICIPATORY DESIGN WORKSHOP
}

\author{
Yanfang ZHANG ${ }^{1}$, Tokushu INAMURA ${ }^{1}$, Shinichiro ITO $^{2}$ and Christian CRUZ $^{3}$ \\ ${ }^{1}$ Kyushu University, Faculty of Design \\ ${ }^{2}$ Kyoto Sangyo University, Faculty of Information Science and Engineering \\ ${ }^{3}$ Yamaguchi University, Faculty of Global and Science Studies
}

\begin{abstract}
The rapid outbreak of COVID-19 pandemic has accelerated the adoption process of digital online tools for social communication across disciplines regardless of cultural backgrounds. Design to had to quickly migrate a considerable portion of its activities to the Internet, making it the preeminent platform in which a large portion of workshops take place nowadays. This swift change from a 'face-to-face' to 'online' reality is by no means without problems and hurdles, a significant one among these, is the scarcity of academic documentation that deals with the workshops from a communication point of view (beyond the technical aspects). This study aims to identify communication problems within 'Online Design Workshops' allowing the organizers to reroute efforts, from a technical and administrative point of view to the quality of the design output itself. The research method adopted was participatory research praxis based on the comparison of survey outputs taken during 'face-to-face' and 'online' workshops conducted between years $2012 \sim 2019$, and 2020, respectively. Using the SMCR model as a framework of communication analysis it was discovered that the most critical aspects are those related to 'understanding' (between participants, of the online tools, and of the contents). Accordingly, a first attempt at optimal heuristic paths to the improvement of design stages within online workshops with focus on communication are proposed. Further design workshops can be approached using the process outlined in this paper, adding to the robustness of the heuristics.
\end{abstract}

Keywords: Design workshop, online workshop, communication methods, SMCR model

\section{BACKGROUND}

Participatory social innovation workshops, hackathons, and similar design-sprint events oriented to solve social issues are held more often than ever before around the world. These events provide fresh and trans figurative methods to increase democratic and bottom-up approaches to innovation, in which participatory models of design has been found to be useful for sustainability and business [1]. In Japan, regular workshops organized by the i.school of the University of Tokyo [2], or social innovation activities by FUJITSU Limited [3] are two well known (among many others) of such events which congregate large numbers of participants from all sorts of professional backgrounds. A design workshop (dWS*), in general terms, differs from other workshops not only, as stated above, in its inclusion of participants with different groundings, but also in the utilization of a 5 stage approach towards finding solutions to problematics: (1) understanding, (2) problem identification, (3) idea development, (4) testing (prototype production), and (5) proposal presentation [4].

*The following denominations are adopted from now on, dWS refers to 'design workshop'. Although the next two are design workshops, both differs in their delivery and are denominated accordingly. f2fdWS refers to face-to-face design workshop', and odWS refers to 'online design workshop'.

This research presents insights on communication via an examination of a series of workshops implemented between years 2012 and 2020. In the period 2012 2019 the workshops carried out were of the f2fdWS type, and in the year 2020 of the odWS type.

Since the classification as a pandemic of the newly detected Corona Virus in 2019, the world has become a virtual (figurative and real) battlefield against the disease. The struggle to regain some sense of normalcy has been fought with all the arsenal at people's disposal, and no other 'weapon' has become more widely used than online communication tools. Although the massive adoption of this new medium 
has been done fairly quickly, it has not been without hindrance. Most of the effort has been concentrated in the deployment of these tools, and in the case of dWS on how to utilize them, however, one would expect the general public to be exposed to a proportional number of resources that deal with communications issues, especially barriers that can affect the workshop's output. Although material of a specialized nature related to the communication process itself can be found using scholarly dedicated methods, a fairly simple and quick search using common and widely available search engines reveals a very different availability. In other words, how the design process is influenced by the use of online tools at a communication level in workshops would greatly benefit from more research being done.

\section{AIMS}

Firstly, this study aims to understand communication issues arising during odWS previously conducted by the authors, leading to heuristics to improve the experience of diverse participants. These would allow the organizers and participants, to focus on the design problematic, as well as creative human interaction, thus increasing the overall quality of the workshop output. Secondly, the study outlines frameworks for identifying issues, and improvements, so that the heuristics may be improved upon with further input.

\section{RESEARCH METHODOLOGY}

The overall methodology was to take the empirical dWS work conducted by the authors/co-organizers, to extract the characteristics of f2fdWS and odWS through the lens of a communication model. Points were then identified to make improvements to communication in odWS. It is important to highlight that as the authors are co-organizers of the dWS, the approach is participatory research praxis. The following subsections explain the methodology in detail.

\subsection{Communication breakdown: applying the SMRC model}

First, multiple models and methods of communication were considered from the literature, in terms of applicability to f2fdWS and odWS. Among the many existing communication models, each one of them focused on a different aspect of the process, being this technical, perceptual, or even psychological [5], [6], the SMRC model was adopted, as proposed by David Berlo [6]. The characteristics and rational for selection are described as follows. In the SMRC model, Berlo defined communication as composed of 4 basic elements, Source, Message, Channel, and Receiver, as shown in Figure 1.

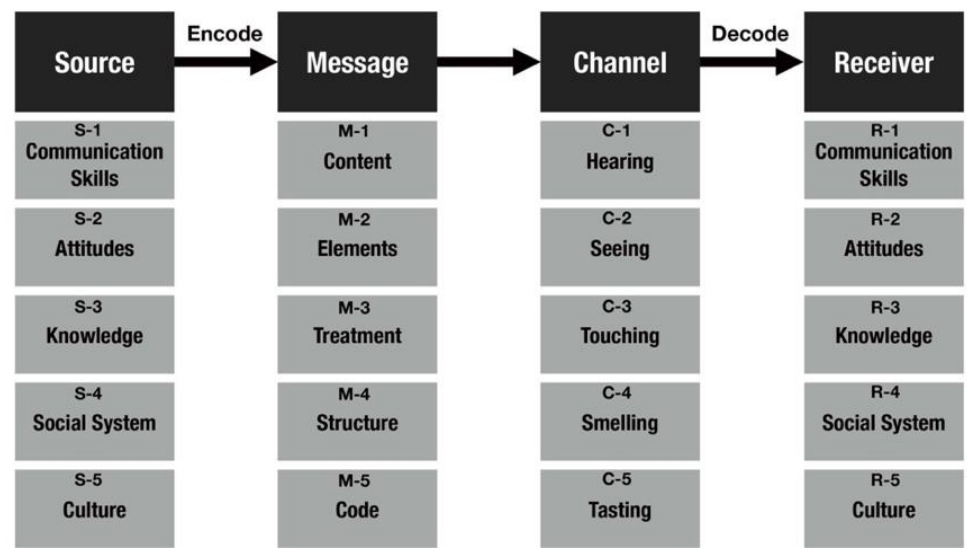

Figure 1. SMCR Model (adapted from businesstopia) [7]

Breaking down the model, the first element of the model is the Source (from here on denoted as $\langle\mathrm{S}\rangle$ ): The sender who originates the message. Second is the Message $\langle\mathrm{M}\rangle$ : The content that is being sent by the sender to the receiver. The third element is the Channel $\langle\mathrm{C}\rangle$ : The medium used to send the message. This is compromised of the human's five senses which are the channels for the communication. The final element is the Receiver $\langle\mathrm{R}\rangle$ : The person who receives the message sent.

The reason for adopting the SMCR model in this study is that:

(1) the SMCR model takes into account the combination of spoken language and non-verbal language such as gestures $\langle\mathrm{M}\rangle$ and the five senses $\langle\mathrm{C}\rangle$. It is therefore a model that captures the types of communication undertaken during dWS, and can highlight the differences between cases, as well as allow for a framework for improvements. 
(2) Compared to f2fdWS, an odWS is not person-to-person but digitally mediated communication. Nonverbal communication such as gestures in $\langle\mathrm{M}\rangle$ and communication through the sense of touch, taste, and smell in the $\langle\mathrm{C}\rangle$ channel are greatly inhibited. Considering all of the above, the SMCR model provides a useful framework to characterize odWS as compared to f2fdWS.

\subsection{Gathering perspectives}

The subjects of the study were the participants and organizers of the f2fdWS conducted between years 2012 and 2019, and odWS in the year 2020. The total number of f2fdWS participants from 2012 to 2019 were 197 in total, with 38 participating in the 2020 odWS.

1) Questionnaire surveys were conducted, composed of structured (multiple choice) and non-structured questions with the inclusion of a Likert-scale in order to measure attitude and predisposition toward the experience of the workshop participation. 2) In order to obtain an organizer perspective that could shed light on the reasoning behind a particular form of communication, structured interviews with a delimited non-dependable set of questions were conducted among the odWS facilitators.

Based on the above survey results and the communication framework provided by the SMCR model, the factors that hinder odWS communication are clarified, the positive points on the odWS communication and the underlying causes are discussed. From these findings, a communication method unique to odWS is proposed.

\section{RESULTS}

\subsection{Questionnaire survey of participants}

In 2020 odWS there were 38 participants of which 31 participants respondents were asked a series of questions regarding their workshop experiences. From these respondents, 7 had also participated in previous f2fdWS, and were administered additional questions about their previous f2fdWS experiences, as seen in Table 1. They were asked to reflect on the differences between the two formats, as well as their backgrounds.

Table 1. Summary of survey results by participants of both f2fdWS and odWS

\begin{tabular}{|c|l|c|l|l|l|}
\hline age & \multicolumn{1}{|c|}{ job } & sex & $\begin{array}{l}\text { when you joined a } \\
\text { past GGJ }\end{array}$ & $\begin{array}{l}\text { Please select reasons you felt this } \\
\text { year online GGJ was more } \\
\text { difficult than offline }\end{array}$ & $\begin{array}{c}\text { What new learnings occurred } \\
\text { during this year online GGJ, } \\
\text { compared to offline }\end{array}$ \\
\hline 35 & designer & $\mathrm{f}$ & $\begin{array}{l}\text { f2fdWS:2016- 2019 } \\
\text { odWS:2020 }\end{array}$ & none & $\begin{array}{l}\text { Total process / Workshop methods / } \\
\text { Online communication tools }\end{array}$ \\
\hline 59 & NPO owner & $\mathrm{f}$ & $\begin{array}{l}\text { f2fdWS:2018, 2019 } \\
\text { odWS:2020 }\end{array}$ & none & $\begin{array}{l}\text { Workshop methods / Refresh activities } \\
\text { / Online communication tools / } \\
\text { Teamwork }\end{array}$ \\
\hline 14 & High school student & $\mathrm{m}$ & $\begin{array}{l}\text { f2fdWS:2019 } \\
\text { odWS:2020 }\end{array}$ & $\begin{array}{l}\text { Online communication tools / } \\
\text { Teamwork }\end{array}$ & $\begin{array}{l}\text { Online communication tools / } \\
\text { Teamwork }\end{array}$ \\
\hline 25 & $\begin{array}{l}\text { University student, } \\
\text { foreigner }\end{array}$ & $\mathrm{f}$ & $\begin{array}{l}\text { f2fdWS:2018, 2019 } \\
\text { odWS:2020 }\end{array}$ & Breaks and lunch & Teamwork \\
\hline 25 & Government office staff & $\mathrm{m}$ & $\begin{array}{l}\text { f2fdWS:2019 } \\
\text { odWS:2020 }\end{array}$ & $\begin{array}{l}\text { Breaks and lunch / Online } \\
\text { communication tools / Teamwork }\end{array}$ & $\begin{array}{l}\text { Total process / Workshop methods / } \\
\text { Refresh activities }\end{array}$ \\
\hline 42 & Company owner & $\mathrm{m}$ & $\begin{array}{l}\mathrm{f} 2 \mathrm{fdWS}: 2018,2019 \\
\text { odWS:2020 }\end{array}$ & $\begin{array}{l}\text { Breaks and lunch / Online } \\
\text { communication tools, }\end{array}$ & $\begin{array}{l}\text { Refresh activities / Online } \\
\text { communication tools }\end{array}$ \\
\hline 23 & $\begin{array}{l}\text { University student, } \\
\text { foreigner }\end{array}$ & $\mathrm{m}$ & $\begin{array}{l}\mathrm{f} 2 \mathrm{fdWS}: 2018,2019 \\
\text { odWS:2020 }\end{array}$ & Teamwork & $\begin{array}{l}\text { Refresh activities / Online } \\
\text { communication tools }\end{array}$ \\
\hline
\end{tabular}

Of the 7 participants, 5 faced difficulties during the odWS. 3 found the odWS communication tool to be a challenge. 3 found the workshop break time and schedule setting to be a challenge, and 3 found difficulty in the teamwork dynamic. Regarding what new learning occurred in the odWS, among the 7 participants, 3 said they learned a lot about odWS methods, 5 said they learned a lot about online communication tools. 4 said the 'refresh activities' were good. This last term, refers to a new activity that was experimented on during the first odWS in 2020. Four of these kinds of activities were introduced to facilitate communication: Tai Chi exercise, radio exercise, mindfulness, and sound meditation. These engage the participants/organizers through physically and mentally embodied which elicit a 'mental reboot', a focus of attention displacement away from the workshop content as described in the literature. The respondents gave positive ratings to these activities. 31 participants who responded to the odWS in 2020 survey gave an approval of $63 \%$ very good, and $27 \%$ good. 


\subsection{Questionnaire survey results from facilitators of odWS}

The 7 facilitators were interviewed regarding the f2fdWS and odWS. The issues and possibilities of odWS compared to f2fdWS are summarized in Table 2.

Table 2. Summary of survey results by facilitators of odWS

\begin{tabular}{|c|c|}
\hline Challenges of odWS & Advantages of odWS \\
\hline $\begin{array}{l}\text { Channel } \\
\text { - The loading of Miro is slow. } \\
\text { Prior training is necessary. } \\
\text { - We may have put too much emphasis on the use of Miro. } \\
\text { - The earphone jack and the place to charge the battery are not enough. Also, the } \\
\text { earphone jack and the place for charging are the same, so we cannot do it } \\
\text { concurrently. } \\
\text { Source/Receiver } \\
\text { - There were many absences without notice which create additional stress for the } \\
\text { organizer. } \\
\text { The intensity of the discussion is worse than face-to-face. } \\
\text { Oveed to provide support for various participants to meet their different needs. } \\
\text { - It would be better if there were a mechanism to encourage interaction between } \\
\text { teams. } \\
\text { - The digital communication tools still pose as an issue for the future, though it } \\
\text { has been easy to use multiple devices and displays. }\end{array}$ & $\begin{array}{l}\text { Channel } \\
\text { - It was easy to refer to the contents, and data collection is much } \\
\text { easier. } \\
\text { - Broadcasting on YouTube allowed families and stakeholders to } \\
\text { watch. } \\
\text { - Slack all odWS active communication and easy viewing after the } \\
\text { event. } \\
\text { - Real-time visualization of other people's work with Miro. } \\
\text { Message } \\
\text { - No need to write. } \\
\text { - The possibility of designing an online experience that demonstrates } \\
\text { communication, such as gestures, which can only happen in person. } \\
\text { - Because it is online, even those who cannot move or live across } \\
\text { regions can participate. } \\
\text { - The combination of different cities and online allowed the } \\
\text { possibility for developing activities in a larger scale. }\end{array}$ \\
\hline
\end{tabular}

\section{DISCUSSION}

Based on the SMCR model, the following facts were understood: The challenges faced using the Channel's communication tools are significant. This may be due to the dWS participants having different skills-abilities, and coming from diverse backgrounds, which consequently has shown different levels of proficiency in communication tools.

The break time and schedule are related to SMCR in general. One particular challenge which was manifested not only in the participant themselves but also at the planification-coordination level was the 'timing' of the programme. The odWS actually takes a toll at a physiological and psychological level of a person required to work in a mostly sedentary mode with long amounts of screen time.

Another particular challenge discovered, was the one related to the teamwork communication skills and attitudes of $\langle\mathrm{S}\rangle$ and $\langle\mathrm{R}\rangle$. Unlike f2fdWS, in odWS the communication is done through a device. A portion of $\langle\mathrm{S}\rangle$ and $\langle\mathrm{R}\rangle$ participants did not show their faces on the screen, this may have affected the intensity of the discussion depending on the participants' attitude.

The facilitator's role is to work from a relatively objective standpoint to facilitate the progress of the overall dWS and group activities when these are carried out and to help the groups perform. Looking at the survey results from this operational support role, further points were highlighted.

Table 3. Summary of factors that inhibit communication in odWS compared to f2fdWS

\begin{tabular}{|c|c|c|c|c|c|}
\hline & (1) Understanding & $\begin{array}{l}\text { (2) Problem } \\
\text { Identification }\end{array}$ & (3) Idea Development & $\begin{array}{l}\text { (4) Testing (prototype } \\
\text { production) }\end{array}$ & $\begin{array}{l}\text { (5) Proposal } \\
\text { Presentation }\end{array}$ \\
\hline Source & $\begin{array}{l}\text { S-1 S-3 Lack of online } \\
\text { encode skills and } \\
\text { knowledge } \\
\text { S-2 S-4 S-5 Insufficient } \\
\text { understanding of other } \\
\text { participants }\end{array}$ & $\begin{array}{l}\text { S-1 S-3 Lack of online } \\
\text { encode skills and } \\
\text { knowledge } \\
\text { S-1 S-2 S-3 Low } \\
\text { participation in } \\
\text { discussions }\end{array}$ & $\begin{array}{l}\text { S-1 S-3 Lack of online } \\
\text { encode skills and } \\
\text { knowledge } \\
\text { S-1 S-2 S-3 Low } \\
\text { participation in } \\
\text { discussions }\end{array}$ & $\begin{array}{l}\text { S-1 S-3 Lack of online } \\
\text { encode skills and } \\
\text { knowledge } \\
\text { S-1 S-2 S-3 Participation } \\
\text { in prototype production } \\
\text { depends on PC skills }\end{array}$ & $\begin{array}{l}\text { S-1 S-3 Lack of online } \\
\text { encode skills and } \\
\text { knowledge } \\
\text { S-2 S-4 S-5 Lack of } \\
\text { understanding of } \\
\text { participants other than } \\
\text { team members }\end{array}$ \\
\hline Message & $\begin{array}{l}\text { M-1 M-2 M-3 M-4 M-5 } \\
\text { Main information from } \\
\text { visual and audio } \\
\text { M-1 M-2 M-3 M-4 M-5 } \\
\text { Lack of non-verbal } \\
\text { gestures and vocal variety }\end{array}$ & $\begin{array}{l}\text { M-1 M-2 M-3 M-4 M-5 } \\
\text { Main information from } \\
\text { visual and audio } \\
\text { M-1 M-2 M-3 M-4 M-5 } \\
\text { Lack of non-verbal } \\
\text { gestures and vocal variety }\end{array}$ & $\begin{array}{l}\text { M-1 M-2 M-3 M-4 M-5 } \\
\text { Main information from } \\
\text { visual and audio } \\
\text { M-1 M-2 M-3 M-4 M-5 } \\
\text { Lack of non-verbal } \\
\text { gestures and vocal variety }\end{array}$ & $\begin{array}{l}\text { M-1 M-2 M-3 M-4 M-5 } \\
\text { Main information from } \\
\text { visual and audio } \\
\text { M-1 M-2 M-3 M-4 M-5 } \\
\text { Lack of non-verbal } \\
\text { gestures and vocal variety } \\
\text { M-1 M-2 M-3 M-4 M-5 } \\
\text { Prototype in the form of } \\
\text { video only }\end{array}$ & $\begin{array}{l}\text { M-1 M-2 M-3 M-4 M-5 } \\
\text { Main information from } \\
\text { visual and audio } \\
\text { M-1 M-2 M-3 M-4 M-5 } \\
\text { Lack of non-verbal } \\
\text { gestures and vocal variety }\end{array}$ \\
\hline Channel & $\begin{array}{l}\text { C-1 C-2 C-3 Depends on } \\
\text { online environment, } \\
\text { equipment, and software } \\
\text { C-1 C-2 Difficult to } \\
\text { collect information other } \\
\text { than sight and hearing }\end{array}$ & $\begin{array}{l}\text { C-1 C-2 C-3Depends on } \\
\text { online environment, } \\
\text { equipment, and software } \\
\text { C-1 C-2 Difficult to use } \\
\text { much software at the } \\
\text { same time } \\
\text { C-1 C-2 Difficult to } \\
\text { collect information other } \\
\text { than sight and hearing }\end{array}$ & $\begin{array}{l}\text { C-1 C-2 C-3Depends on } \\
\text { online environment, } \\
\text { equipment, and software } \\
\text { C-1 C-2 Difficult to use } \\
\text { much software at the } \\
\text { same time } \\
\text { C-1 C-2 Difficult to } \\
\text { collect information other } \\
\text { than sight and hearing }\end{array}$ & $\begin{array}{l}\text { C-1 C-2 C-3Depends on } \\
\text { online environment, } \\
\text { equipment, and software } \\
\text { C-1 C-2 Difficult to } \\
\text { prototype though five } \\
\text { senses }\end{array}$ & $\begin{array}{l}\text { C-1 C-2 C-3 Depends on } \\
\text { online environment, } \\
\text { equipment, and software } \\
\text { C-1 C-2 Difficult to } \\
\text { collect information other } \\
\text { than sight and hearing }\end{array}$ \\
\hline Receiver & $\begin{array}{l}\text { R-1 R-3 Lack of online } \\
\text { decode skills and } \\
\text { knowledge } \\
\text { R-2 R-4 R-5 Insufficient } \\
\text { understanding of other } \\
\text { participants }\end{array}$ & $\begin{array}{l}\text { R-1 R-3 Lack of online } \\
\text { decode skills and } \\
\text { knowledge } \\
\text { R-1 R-2 R-3 Low } \\
\text { participation in } \\
\text { discussions }\end{array}$ & $\begin{array}{l}\text { R-1 R-3 Lack of online } \\
\text { decode skills and } \\
\text { knowledge } \\
\text { R-1 R-2 R-3 Low } \\
\text { participation in } \\
\text { discussions }\end{array}$ & $\begin{array}{l}\text { R-1 R-3 Lack of online } \\
\text { decode skills and } \\
\text { knowledge } \\
\text { R-1 R-2 R-3 Participation } \\
\text { in prototype production } \\
\text { depends on PC skills }\end{array}$ & $\begin{array}{l}\text { S-1 S-3 Lack of online } \\
\text { decode skills and } \\
\text { knowledge } \\
\text { S-2 S-4 S-5 Lack of } \\
\text { understanding of } \\
\text { participants other than } \\
\text { team members }\end{array}$ \\
\hline Overall & \multicolumn{5}{|c|}{$\begin{array}{l}\text { - Difficult to plan the workshop with diverse participants. } \\
\text { - Difficult to provide technical support to diverse participants. } \\
\text { - Difficult to provide emotion support to diverse participants. }\end{array}$} \\
\hline
\end{tabular}


For the $\langle\mathrm{C}\rangle$ issues, unlike the results of the first survey, the facilitators viewed the issues not only from the perspective of the communication tools, but also from a larger perspective of the internet facilities and participation environment. In the case of $\langle\mathrm{S}\rangle$ and $\langle\mathrm{R}\rangle$, more support was needed for the various participants. At the same time, the facilitators had to spend a considerable amount of time getting acquainted with the technical aspects (usability) of the digital tools, which added to their scope of responsibilities, requiring extra effort. The surveys also showed the possibility of new methods of active $\langle\mathrm{C}\rangle$ and $\langle\mathrm{M}\rangle$ processing in odWS and the necessity of new methods suited for the online medium.

From the above results, the odWS communication compared to f2fdWS showed concrete deficiencies from a technological perspective $\langle\mathrm{C}\rangle$, teamwork between participants $\langle\mathrm{S} / \mathrm{R}\rangle$, and the overall design process communication performance was negatively impacted at all levels $\langle\mathrm{S} / \mathrm{M} / \mathrm{C} / \mathrm{R}\rangle$, including the 'non-structured' (casual) communication at break times. The summary of the factors that hinder communication in odWS are listed for each process in Table 3.

A dWS is an activity that if correctly implemented may be able to not only provide concrete output in the form of services or products, but also create a powerful base for social impact, however, the issues highlighted in Table 3 show that odWS have many issues that need to be addressed to reach its potential. The heuristic paths to improvement have been summarized below in Table 4.

Table 4. Proposed methods to improve communication for diverse participants in odWS

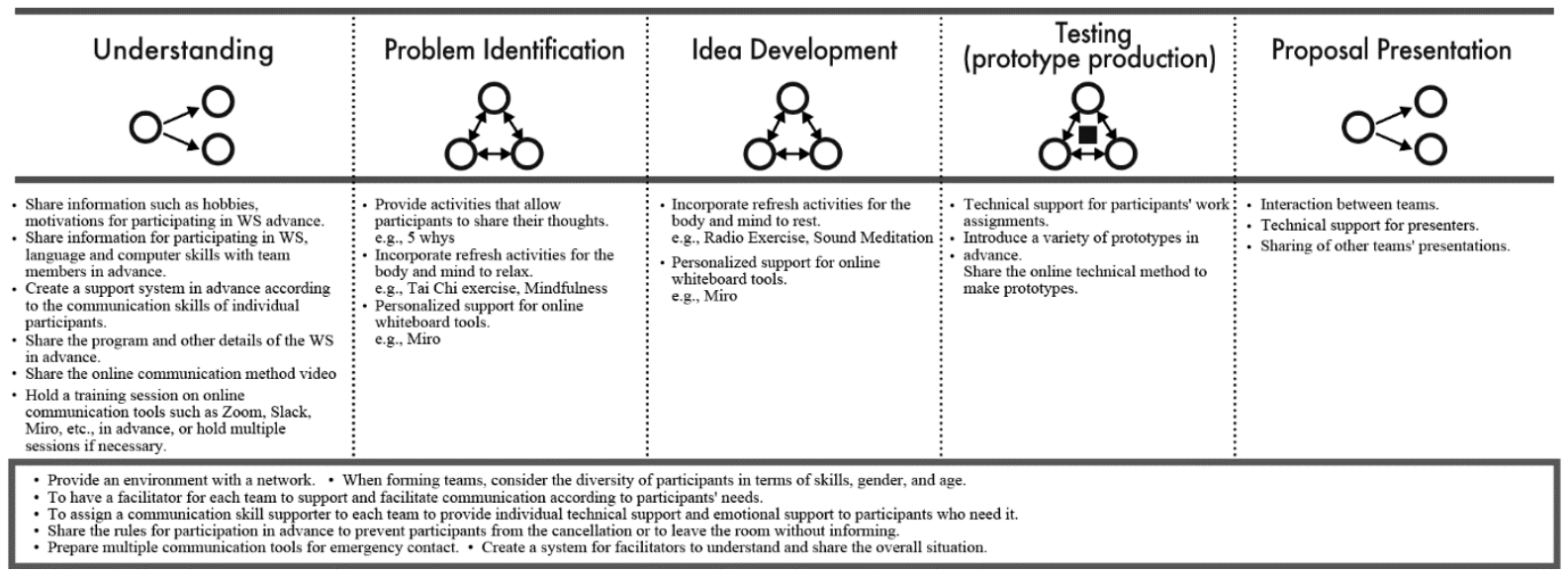

The table organizes the dWS into five stages with common issues listed in the square underneath. It is worth mentioning important factors in each stage. In order to have good communication, at the first stage, understanding must be of a pre-emptive nature, that is to say, good comprehension among participants, of the concept, of contents of the dWS, and of the online communication tools at a technical level should be done prior to the problem identification where the focus should be concentrated of the design issues itself. At the problem identification and idea development stages, it is important to ensure each participant with enough online resources, so ideas are easily conveyed and omnipresent (constantly visible and accessible by all participants) this facilitates awareness, idea diffusion, and convergence.

'Refreshing activities' such as Tai Chi exercise, mindfulness, among others, should not be taken lightly, although reduced in their scope and direct influence at the design level itself, their impact could greatly amplify the quality of the ideation stage in which focused analytical, yet highly abstract thinking is necessary.

Prototyping, even in $\mathrm{f} 2 \mathrm{fdWS}$ is a complex issue. More often than not, participants misplace the focus of this stage on the technical aspects related to 'make the design solution work (as in function)' rather than in conveying 'how the product under a particular set of circumstances should operate'. In an odWS, participants should be provided with the technical means necessary to communicating the optimal operational conditions of a design solution. Organizers should confirm the correct understanding and usability of any prototyping tool in advance, even to the workshop itself (e.g., registration period).

In the Presentation stage, technical expertise and total (as much as possible) control over the technical aspects of the delivery (signal, connection, sound, image quality, etc.) is crucial. An unpredictable or unstable environment not only will hinder the communication by reducing the effort invested in the workshop to useful but undeliverable information, but also could potentially exert a hard impact at an emotional and psychological level of the participants preventing them to take part in these kinds of 
events again. Organizers should prepare a 'plan B', made known to all participants in advance, in the case that optimal online live delivery cannot be secured.

In addition, it is very important to create a fair, democratic, interactive, and open environment in which every participant and team can express, share, and exchange ideas and feel accepted regardless of their background, and specially in odWS, their connectivity. Activities which are designed or adapted to be carried out in online environments can be benefited by the adoption of a communicative approach based on the SMCR model. At first, it may not be easy for the participants to reach an optimal level of performance at the $\langle\mathrm{C}\rangle$ due to the multiple layers of computing requirements. Hence, it is of core value to design an understanding of what an optimal $\langle\mathrm{M}\rangle$ should be for an online domain, especially one in which the bidirectional interaction between Source and Receiver is flawlessly realized. This kind of understanding requires a wide and novel array of approaches. Case in point, the 'refresh activities' incorporated in the odWS in 2020.

\section{CONCLUSIONS}

This study is a first attempt to extract problems identified during odWS using the SMRC model and suggest paths to improvement through along a five stage dWS framework. The proposed method for improvement increases the chance of success communication during online participatory workshops with diverse participants. Thus, enabling the workshop organizers who focus on elements of the workshop that are more critical for the qualitative outcomes.

Considering the survey analysed data, when compared to f2fdWS, since odWS is not person-to-person but (computing) device-mediated communication, Non-verbal communication such as gestures and communication through the sense of touch, taste, and smell in the $\langle\mathrm{C}\rangle$ are greatly inhibited. In order to improve it, coordination in $\langle\mathrm{S}, \mathrm{M}, \mathrm{R}\rangle$ is crucial, and for $\langle\mathrm{M}\rangle$, It is suggested that taking advantage of online digital tools to collect information and assemble it in a way that is psychologically and emotionally relevant to the participants at $\langle\mathrm{S}\rangle$ and $\langle\mathrm{R}\rangle$ ends is key (pre-emptive understanding).

As a first attempt, the proposed heuristics suggested in this paper are by no means final. Further dWS can be approached using the process outlined in this paper, adding to the robustness of the heuristics.

Finally, under the dawn of the massive vaccination programmes currently under implementation, the world will eventually regain some semblance of similarity analogous to a pre-pandemic condition. However, even with paths to improvement at hand, we should be prepared for the scenario that the need for online activities, including workshops, increase and diversify. The significance of this research is a direct contribution to the diverse stakeholders of dWS equally across education and for/non-profit sectors.

\section{REFERENCES}

[1] Björgvinsson E., Ehn P., and Hillgren P-A. Participatory design and "democratizing innovation". Proceedings of the 11th Biennial Participatory Design Conference. Association for Computing Machinery, New York, NY, USA, 2010, pp.41-50.

[2] i.school the University of Tokyo, Available: https://ischool.or.jp, [Updated October 2020, Accessed on 2021, February], (2021) February.

[3] Hirano T., Ishizuka A. and Sakaguchi K. Innovation Activities by Co-creation Process, The journal of Fujitsu, 4,2, 2013 pp.127-133

[4] Zhang Y. Diversity, sustainability, and inclusivity through collaborative design workshop for local issues (case study), The 3rd International Conference on Healthcare, SDGs, and Social Business. Nov.19-21, 2019

[5] Wenxiu P. Analysis of New Media Communication Based on Lasswell's "5W" Model. Journal of Educational and Social Research, 5(3), 2015. pp.245-250.

[6] Shinoda I. and Isono H. Consideration on information and communication, The journal of Kawamura Gakuen Woman's University, 1996, 7(2) pp.1-16

[7] Berlo's SMCR Model of Communication, businesstiopia, Available: https://www.businesstopia. net/communication/berlo-model-communication, [Updated January 6, 2018, Accessed on 2021, January], (2021) January. 